\title{
Comparative analysis of turning and traverse grinding of bearing steel parts in hardened state
}

Jarosław PLICHTA, Krzysztof NADOLNY, Sylwester WOJCIESZAK

DOI: $10.30464 /$ jmee.2018.2.2.89

Cite this article as:

Plichta J., Nadolny K., Wojcieszak S. Comparative analysis of turning and traverse grinding of bearing steel parts in hardened state. Journal of Mechanical and Energy Engineering, Vol. 2(42), No. 2, 2018, pp. 89-94.

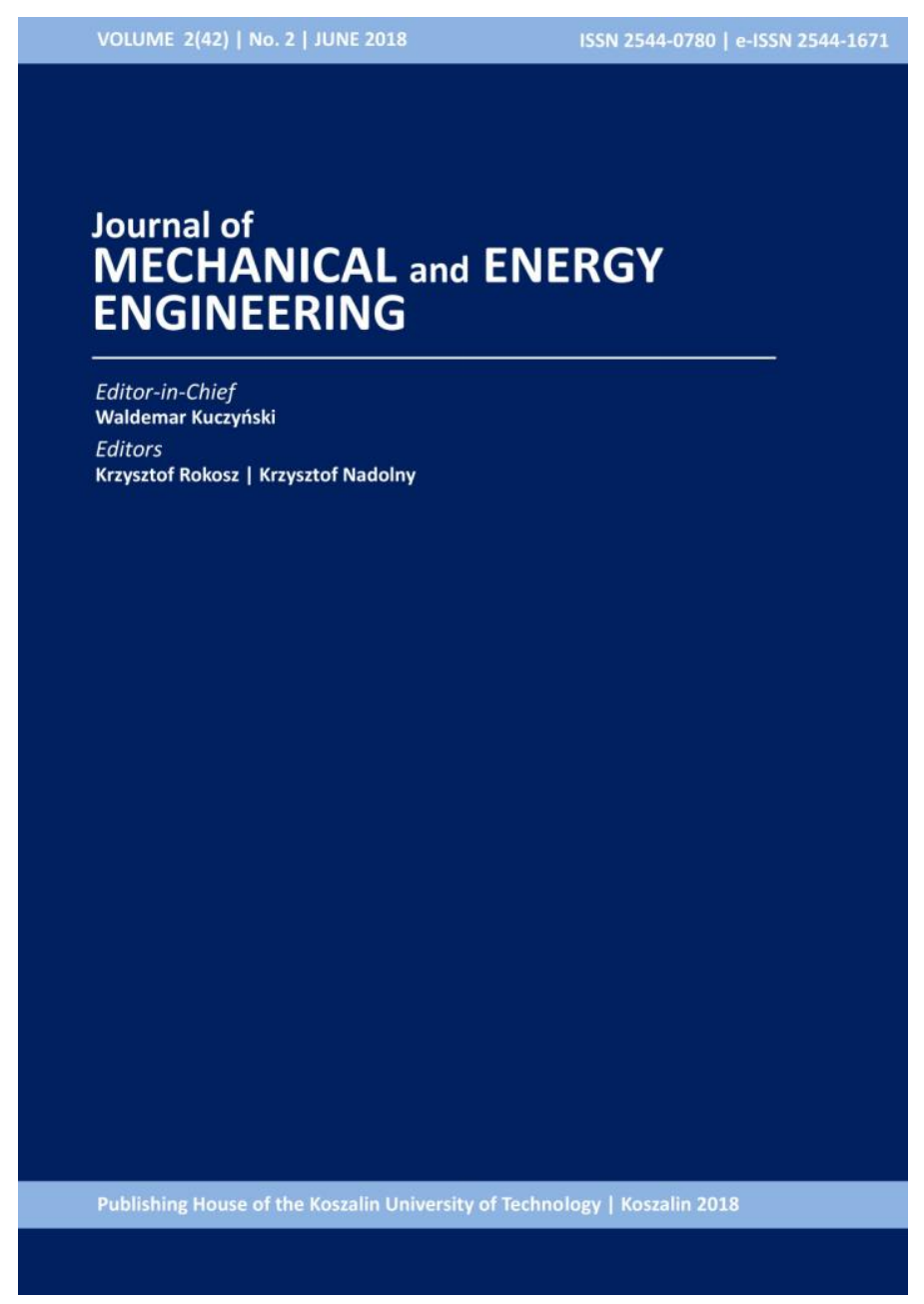

\section{Journal of Mechanical and Energy Engineering}

Website: jmee.tu.koszalin.pl

ISSN (Print): 2544-0780

ISSN (Online): 2544-1671

Volume: $2(42)$

Number: 2

Year: 2018

Pages: 89-94

\section{Article Info:}

Received 19 January 2018

Accepted 15 February 2018

\section{Open Access}

This article is distributed under the terms of the Creative Commons Attribution 4.0 (CC BY 4.0) International License (http://creativecommons.org/licenses/by/4.0/), which permits unrestricted use, distribution, and reproduction in any medium, provided you give appropriate credit to the original author(s) and the source, provide a link to the Creative Commons license, and indicate if changes were made. 


\title{
COMPARATIVE ANALYSIS OF TURNING AND TRAVERSE GRINDING OF BEARING STEEL PARTS IN HARDENED STATE
}

\author{
Jarosław PLICHTA ${ }^{1 *}$, Krzysztof NADOLNY ${ }^{2}$, Sylwester WOJCIESZAK ${ }^{2}$ \\ ${ }^{1 *}$ Faculty of Mechanical Engineering, Department of Production Engineering, Koszalin University \\ of Technology, Raclawicka 15-17, 75-620 Koszalin, Poland, e-mail: jaroslaw.plichta@tu.koszalin.pl \\ ${ }^{2}$ Faculty of Mechanical Engineering, Department of Production Engineering, \\ Koszalin University of Technology, Poland
}

(Received 19 January 2018, Accepted 15 February 2018)

\begin{abstract}
The article describes the results of experiments which were intended to compare the results of turning and traverse grinding of internal cylindrical surfaces of rings made of bearing steel $(100 \mathrm{Cr} 6)$ in hardened state $(62 \pm 2 \mathrm{HRC})$. During experimental investigations, particular attention was paid to the machining performance and roughness of the machined surface. The results of the research presented in this article confirm the advantage of the turning process over traverse grinding using grinding wheels with zone-diversified structure.
\end{abstract}

Keywords: turning, traverse grinding, bearing steel, surface roughness, process efficiency

\section{INTRODUCTION}

With the constant desire to minimize costs and improve the quality of machining, turning hardened materials is increasingly becoming an alternative to grinding processes. This is due to the many advantages of this processing, which include [4-6, 10]:

- less financial outlays at the investment stage, resulting from: lower costs of lathes compared to grinding machines, fewer machines in the technological process, savings of working area;

- shorter processing unit time due to: the possibility of carrying out many operations on one machine, shortening of preparation and finishing times, high level of integration of processing;

- high flexibility of machining resulting from: obtaining complex shapes with various types of tools, speed of tool change, processing support with advanced CAD/CAM systems;

- more ecological production due to: the possibility of processing without cooling lubricant, ease of chip collection and recycling, lower unit energy costs.

Synthetically, the comparison between grinding and turning is shown in Figure 1.
Owing to these advantages, workpieces in the hardened state are increasingly used in automotive, bearing, hydraulic system components, mould and die machining [6].

The results of comparative tests carried out on grinding and turning of external cylindrical surfaces made of $100 \mathrm{Cr} 6$ steel $(62 \mathrm{HRC})$ confirm in many aspects the advantage of machining in hardened state (Tab. 1).

Such analyses have so far been carried out only with respect to conventional grinding methods, using standard tools [1-3]. However, it is important to bear

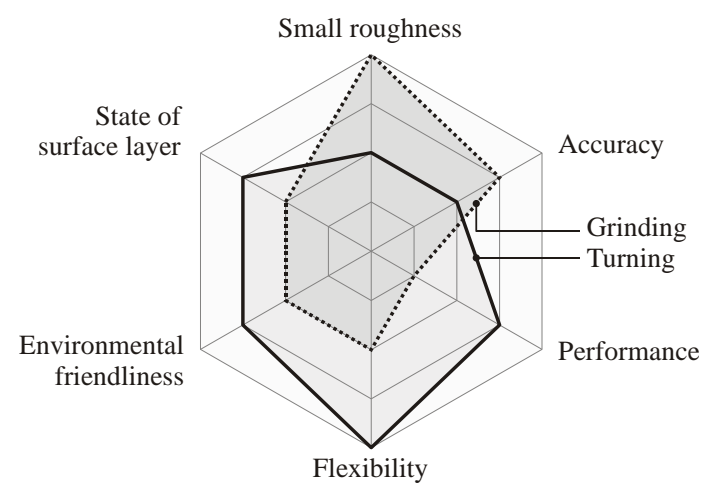

Fig. 1. Comparison of selected features of the grinding and cutting process 
Tab. 1. Comparative evaluation of turning and grinding of materials in hardened state [4-6]

\begin{tabular}{lccc}
\hline Parameter & Unit & Turning & Grinding \\
\hline $\begin{array}{l}\text { Surface } \\
\text { roughness }\end{array}$ & $R z, \mu \mathrm{m}$ & 3.5 & 3.0 \\
\hline Tool life & $\begin{array}{c}\text { Machined } \\
\text { workpieces }\end{array}$ & 1000 & 150 \\
\hline $\begin{array}{l}\text { Tool change } \\
\text { time }\end{array}$ & min/month & 25 & 231 \\
\hline $\begin{array}{l}\text { Machining } \\
\text { time }\end{array}$ & min & 0.17 & 0.5 \\
\hline Staff costs & PLN/pcs. & 0.034 & 0.100 \\
\hline $\begin{array}{l}\text { Cost of the } \\
\text { tool }\end{array}$ & PLN/pcs. & 0.022 & 0.014 \\
\hline $\begin{array}{l}\text { Cost of } \\
\text { equipment }\end{array}$ & PLN/pcs. & 0.024 & 0.108 \\
\hline Total cost & PLN/pcs. & 0.08 & 0.222 \\
\hline
\end{tabular}

in mind that abrasive processes are also subject to continuous development, both in terms of processing kinematics and the construction of abrasive tools. It is therefore interesting to compare technical and economic parameters of hard cutting with innovative grinding methods. With regard to the processing of internal cylindrical surfaces, such a method is traverse grinding using grinding wheel with zone-diversified structure [9].

The aim of this study was to compare the results of turning and traverse grinding of internal surfaces of rings made of bearing steel $(100 \mathrm{Cr} 6)$ in hardened state.

\section{CHARACTERISTIC OF TRAVERSE GRINDING USING GRINDING WHEELS WITH ZONE-DIVERSIFIED STRUCTURE}

The essence of one traverse grinding is to remove the total machining allowance in only one pass of the grinding wheel, which in the front part has a shaped conical chamfer, allowing to extend the coarse zone of rough grinding and to separate it from the finish grinding zone (Fig. 2).

In this grinding process, there are four variable load zones for the abrasive tool (Fig. 2a). In Zone I, the load increases steadily until it reaches a constant value. In Zone II, the load value remains constant and is proportional to the appropriate material removal. In Zone III, the load decreases in the same way as in Zone I. Zone IV is followed by finish grinding with a small machining allowance. In the first three zones, the vast majority of excess machining is carried out in a highly efficient manner and the final surface finish is achieved in the fourth zone.

In order to ensure the proper efficiency of the traverse internal cylindrical grinding process, as well as to minimize the micro- and macro-wear of abrasive

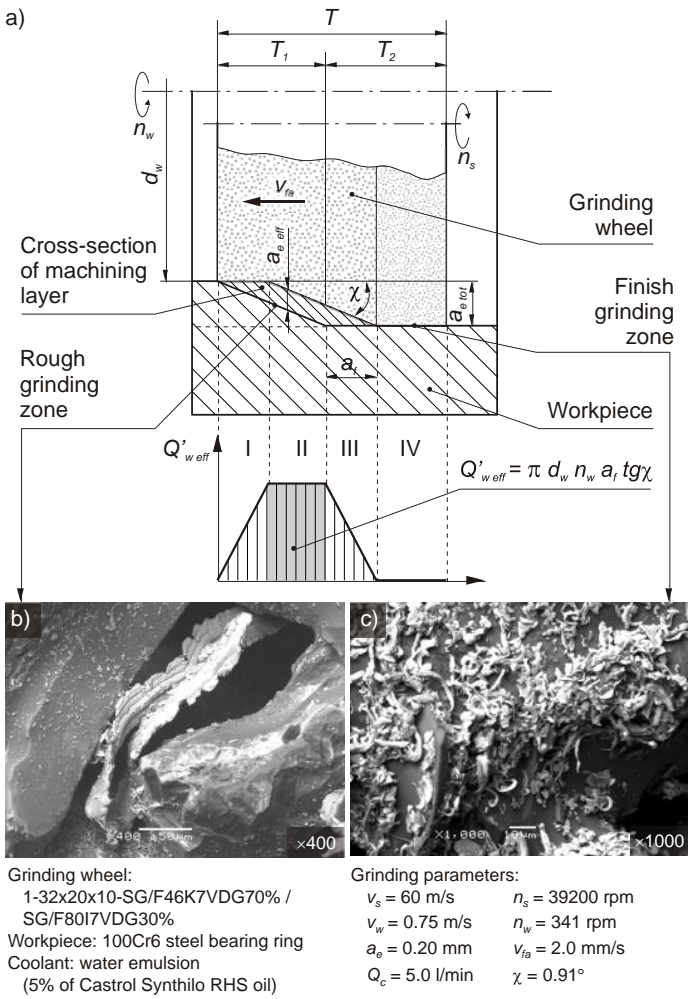

Fig. 2. Operating load on the grinding wheel active surface (a) and views of chips from the rough (b) and finish grinding zones (c) of traverse internal cylindrical grinding using grinding wheel with conic chamfer and zone-diversified structure [9]

tools, grinding wheels with zone-diversified structure are used (Fig. 3).

Zone-diversified structure grinding wheels are characterized by the fact that the rough grinding zone is made up of relatively large grains and the finish grinding zone has a significantly smaller grain size. A more open structure is also introduced in the conical zone.

In the Department of Production Engineering of the Koszalin University of Technology, a study on the internal cylindrical traverse grinding of bearing rings made of $100 \mathrm{Cr} 6$ steel $(62 \pm 2 \mathrm{HRC})$ with the use of zone-differentiated structure grinding made of $\mathrm{Al}_{2} \mathrm{O}_{3}$ abrasive grains showed a significant increase in the efficiency of this process in relation to typical reciprocal grinding process. This increase can reach up to $76 \%$ [7] (Fig. 4).

This increase is strongly dependent on the feed rate of the grinding wheels. In the case of zonediversified grinding wheels with abrasive grains of submicrocrystalline sintered corundum, it is expected that the machining efficiency can be further increased by providing a low surface roughness as well as good surface layer properties. 
a)

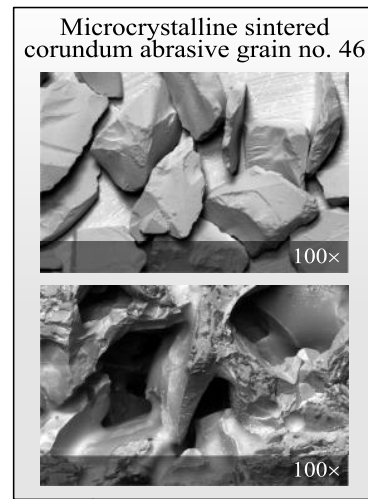

b)
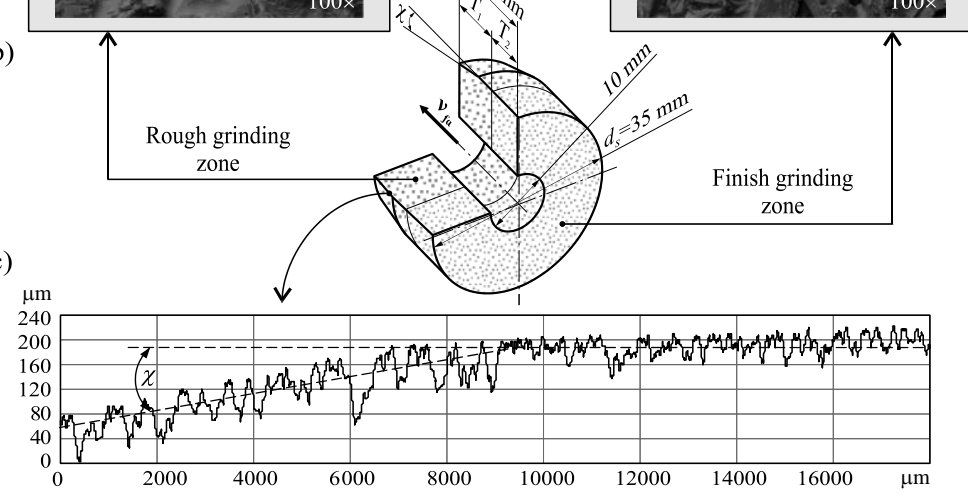

Fig. 3. Zone-diversified structure grinding wheel made of submicrocrystalline sintered corundum abrasive grains no. 46 in conical rough grinding zone (a) and no. 80 in cylindrical finish grinding zone (b), which results in diversified microgeometry of the grinding wheel active surface (c) [8]

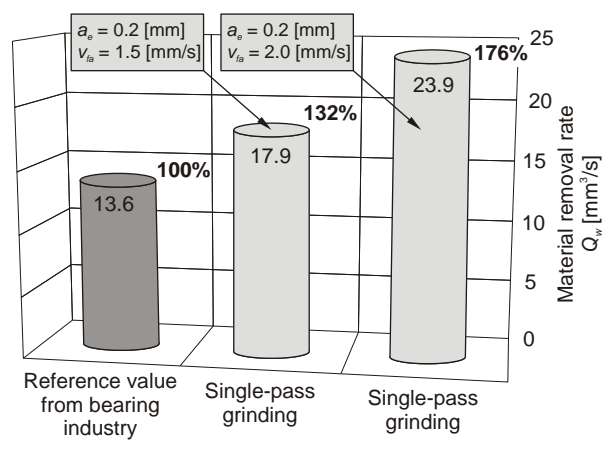

Fig. 4. Comparison of material removal $Q w$ for conventional reciprocal grinding (data from the bearing factory) and traverse process [7]

\section{EXPERIMENTAL RESEARCH}

The aim of the experimental research was to compare the traverse grinding and turning of internal cylindrical surfaces in rings made of bearing steel $100 \mathrm{Cr} 6(62 \pm 2 \mathrm{HRC})$ with an internal diameter of $d_{w}=40 \mathrm{~mm}$. Particular attention was paid to the machining performance and roughness of the machined surface.

\subsection{Turning process}

Research of the turning process was conducted on the lathe center type CTX 310 by DMG Gildemeister (Fig. 5).
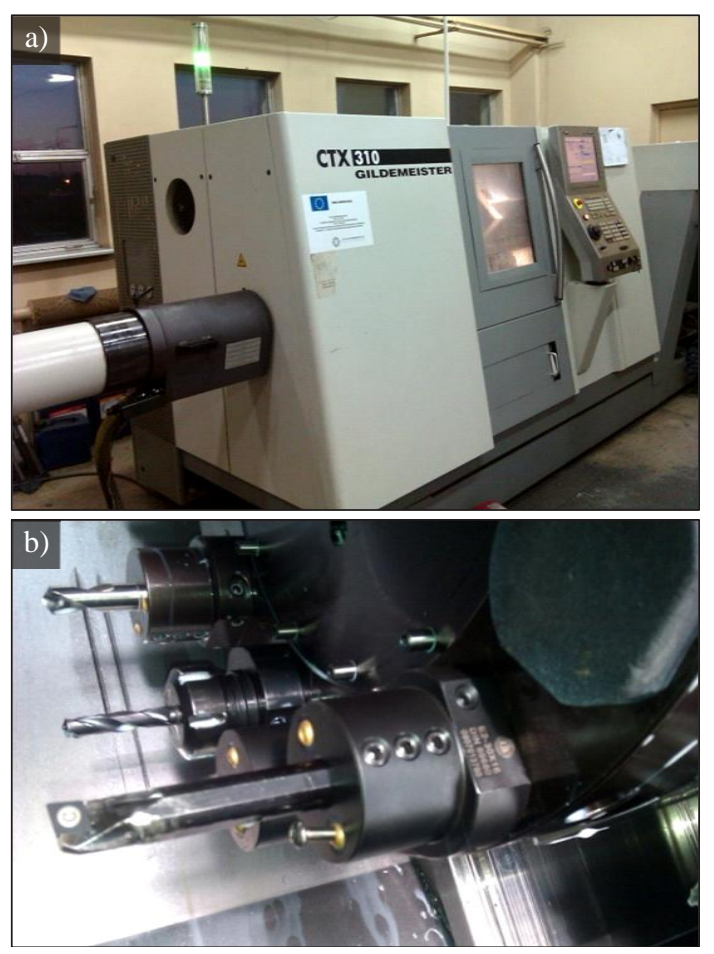

Fig. 5. Lathe center type CTX 310 by DMG Gildemeister: a) overall view; b) view of turning tool used in the experiments 
The cutting tool used was equipped with a sintered carbide cutting insert type ORION WSP CCMW 09T308 6605. During turning following values of process parameters were applied: cutting depth $a_{p}=0.10 \mathrm{~mm}$, cutting speed $v_{c}=200$ and $250 \mathrm{~m} / \mathrm{min}$ and feed rate $f_{t}=0.01,0.05$ and $0.10 \mathrm{~mm} / \mathrm{rev}$.

An example of a surface roughness profile after turning was shown in Figure 6.

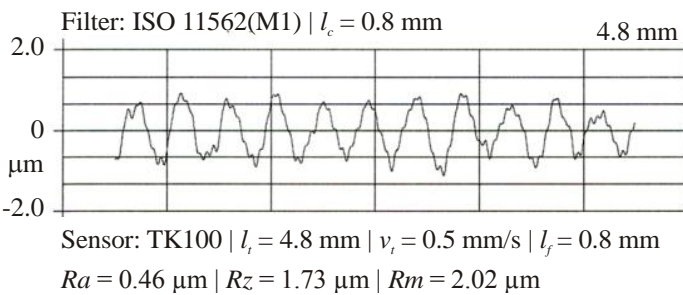

Fig. 6. Roughness profile and selected roughness parameters of surface after turning $\left(a_{p}=0.10 \mathrm{~mm}\right)$

This profile is characterized by a high degree of regularity, which is the result of a geometrically determined cutting trace of the tool tip. Its frequency characteristics depend on the feed value of the tool, while the amplitude characteristics depend mainly on the depth of cutting. These characteristics are also influenced by the material shaping conditions in the machining zone and vibration of the machining system.

The cumulative results of workpiece surface roughness measurements after turning were shown in Figure 7.

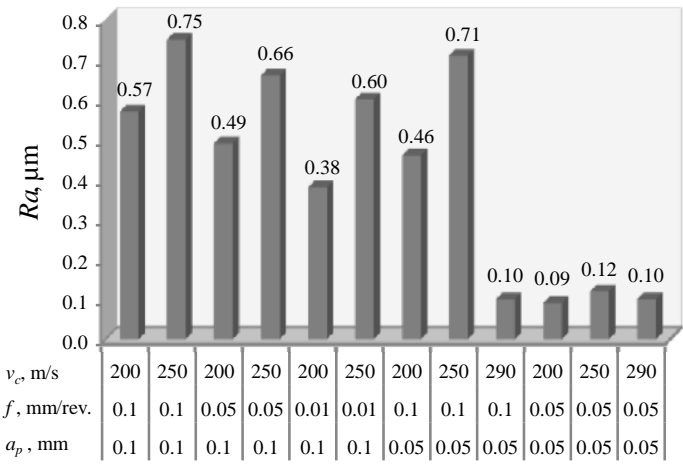

Fig. 7. Change of the $R a$ parameter of workpiece surface roughness depending on the turning process conditions

The analysis of these results showed that the lowest values of $R a$ parameter that describes surface roughness after machining was obtained with the following turning parameters: $v_{c}=200 \mathrm{~m} / \mathrm{min}$, $v_{t}=0.01 \mathrm{~mm} / \mathrm{rev}$ and $a_{p}=0.10 \mathrm{~mm}$. With these parameters material removal was $Q_{w}=1.66 \mathrm{~mm}^{3} / \mathrm{s}$. This performance is of a relatively low value and it is characteristic for precision turning of workpieces in hardened state. On the one hand, it is dictated by ensuring the lowest possible roughness of the workpiece surface, and on the other hand by ensuring proper condition of its surface layer.

\subsection{Traverse grinding process}

The internal cylindrical traverse grinding process was carried out on a RUP 28P grinder by Tarnów SA equipped with an electro-spindle type EV-70/70-2WB by Fischer with control system (Fig. 8). This spindle can achieve a speed of up to $60,000 \mathrm{rpm}$.

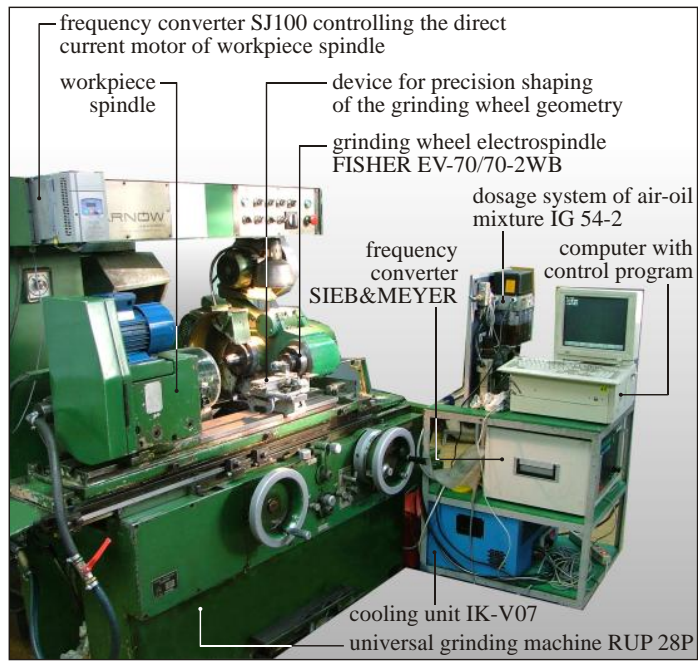

Fig. 8. Experimental setup equipped with grinding machine type RUP 28P by Tarnów SA

As in the case of turning, internal cylindrical internal surfaces of $100 \mathrm{Cr} 6$ steel were ground. In the process, zone-diversified grinding wheels made of submicrocrystalline sintered corundum abrasive grains of various grain sizes were used. In the rough grinding zone, the grit size was the same for all the grinding wheels used and was no. 46, whereas in the finish grinding zone, a variable grit no. of 60 and 80 was used. Dressing cut using a single-grain diamond dresser was applied before each grinding operation. The angle of conic chamfer in the rough grinding zone has also been shaped in the dressing cut.

The tests were carried out with the following parameters: $v_{s}=60 \mathrm{~m} / \mathrm{s} ; \quad v_{w}=0.75 \mathrm{~m} / \mathrm{s}, \quad v_{f a}=1.0$ and $2.0 \mathrm{~mm} / \mathrm{s}$.

An example of a surface roughness profile after grinding was shown in Figure 9.

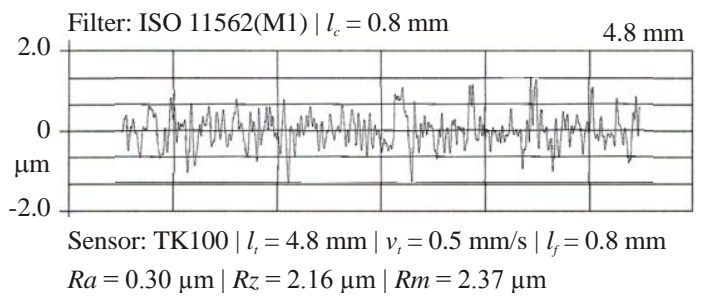

Fig. 9. Roughness profile and selected roughness parameters of surface after grinding $\left(a_{e}=0.20 \mathrm{~mm}\right)$ 
The characteristic feature of this profile is the high level of anisotropicity, which is the result of the action of randomly contacting abrasive grains with the workpiece surface and a high level of material deformation in the grinding zone. Its shape is significantly influenced by the topography of the active surface of the grinding wheel in the finish grinding zone, resulting from the shape, size and distribution of the abrasive grains.

The cumulative results of workpiece surface roughness measurements after internal cylindrical traverse grinding process were shown in Figure 10.

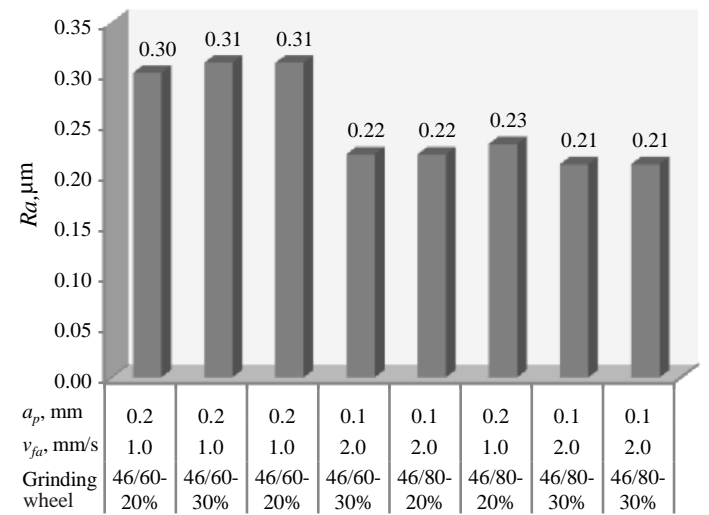

Fig. 10. Change of the $R a$ parameter of workpiece surface roughness depending on the grinding wheel characteristic and traverse grinding conditions (vales $20 \%$ and $30 \%$ describes the share of finish grinding zone in the entire width of the grinding wheel)

The lowest values of surface roughness $R a$ parameter are close to $0.20 \mu \mathrm{m}$, with a grinding depth of $a_{e}=0.1 \mathrm{~mm}$. This is independent of the characteristics of the grinding wheels tested and the axial feed rate. Even up to a 2 -fold increase in feed rate from 1.0 to $2.0 \mathrm{~mm} / \mathrm{s}$ (resulting in a 2-fold increase in material removal rate) does not significantly worsen workpiece roughness. This is the effect of the finish grinding zone of the grinding wheel active surface. Increasing the grinding depth from 0.1 to $0.2 \mathrm{~mm}$ increases the values $R a$ parameter from approx. $0.2 \mu \mathrm{m}$ to approx. $0.3 \mu \mathrm{m}$.

\subsection{Comparative assessment of turning and traverse grinding processes}

The analysis of experimental results shows that in the case of the finish machining of internal cylindrical surfaces of workpieces in hardened state, the traverse grinding is qualitatively competitive in relation to turning. This is due to the modification (extension) of the rough grinding zone due to the introduction of a conic chamfer in the rough grinding zone and the introduction of relatively small grains with submicrocrystalline structure into the finish grinding zone.

It should be noted, however, that despite the fact that the traverse grinding shows significant progress in terms of efficiency in relation to the reciprocal grinding, it is not competitive in relation to turning (Tab. 2)

Tab. 2. Comparative characteristics of internal cylindrical turning and traverse grinding processes of $100 \mathrm{Cr} 6$ bearing steel rings (62 2 HRC): $t_{p c}$ - preparatory and completion time, $t$-machining time

\begin{tabular}{lcc}
\hline \multicolumn{1}{c}{ Parameter } & Turning & $\begin{array}{c}\text { Traverse } \\
\text { grinding }\end{array}$ \\
\hline$R a, \mu \mathrm{m}$ & 0.38 & 0.21 \\
\hline$Q_{w}, \mathrm{~mm}^{3} / \mathrm{s}$ & 2.5 & 0.625 \\
\hline$t_{p c}, \mathrm{~min} / \mathrm{pcs}$ & 1.2 & 2.3 \\
\hline$t, \mathrm{~min}$ & 0.125 & 0.3 \\
\hline
\end{tabular}

This is due to the significant progress in the development of cutting tools, including relatively inexpensive fine-dispersion sintered carbide cutting inserts. This results in a relatively higher turning performance and shorter preparation time, which in the case of traverse grinding is needed to make a conical chamfer on the grinding wheel active surface in the dressing procedure.

It should be borne in mind, however, that the surface structures shaped in these processes differ significantly (Fig. 11).
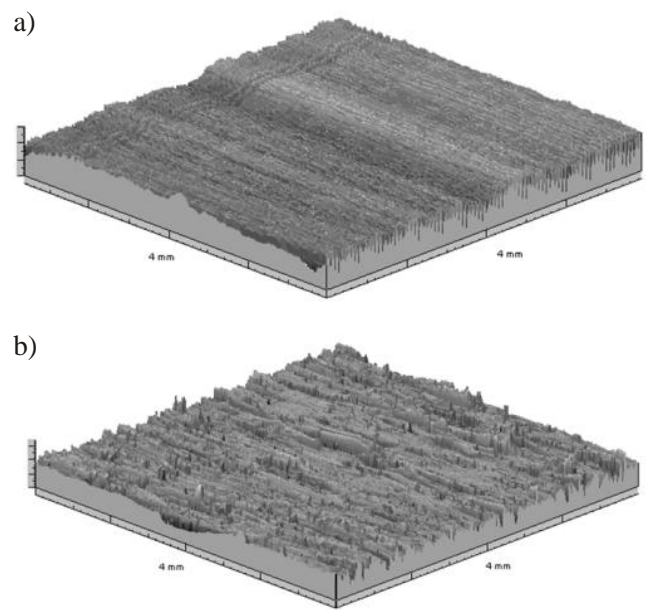

Fig. 11. Workpiece surface geometric structure: a) after turning; b) after grinding

The surface after turning process is characterized by parallel machining marks. On the other hand, the surface after grinding does not have any clearly visible periodic components and has a much more developed structure. It is characterized by a relatively large number of randomly oriented submicrounevenness. In the practical sense these features significantly differentiate their properties, e. g. tribological properties, bearing capacity, adhesion and corrosion resistance. It should also be expected that there are different properties of their surface layer, such as microhardness, distribution and state of residual stresses. 


\section{CONCLUSIONS}

Comparative studies conducted so far on the processes of machining materials in hardened state and grinding processes have been carried out mainly in relation to external surfaces. The results of research presented in this article concerning the machining of internal cylindrical surfaces also confirm the advantage of the turning process over traverse grinding, which is characterized by a relatively high efficiency in relation to reciprocal grinding. However, it should be emphasized that it allows one to obtain significantly lower roughness of the machined surface. Surface roughness after turning may be significantly reduced by using cubic boron nitride inserts with smoothing edge. This, however, requires high-speed machining at very low depths of cut and puts high demands on technological machines.

In order to rationally apply both of these processes, it is necessary to take into account the state of the workpiece surface layer, especially the presence of an unfavorable so-called white layer. Its formation is related to the amount of heat generated in the cutting zone, especially depending on the depth of the cut and the degree of tool wear. This is particularly important for workpieces with high technical and operational requirements.

\section{References}

1. Grzesik W., Żak K., Kiszka P. (2014) Comparison of surface textures generated in hard turning and grinding operations. Procedia CIRP, Vol. 13, pp. 84-89. DOI: 10.1016/j.procir.2014.04.015.

2. Grzesik W., Żak K. (2013) Producing high quality hardened parts using sequential hard turning and ball burnishing operations. Precision Engineering, Vol. 37, No. 4, pp. 849-855. DOI: 10.1016/j.precisioneng. 2013.05.001.

3. Grzesik W., Żak K. (2012) Modification of surface finish produced by hard turning using superfinishing and burnishing operations. Journal of Materials Processing Technology, Vol. 212, No. 1, pp. 315-322. DOI: 10.1016/j.jmatprotec.2011.09.017.

4. Guo Y.B, Sahni J. (2004) A comparative study of hard turned and cylindrically ground white layers. International Journal of Machine Tools and Manufacture, Vol. 44, No. 2-3, pp. 135-145. DOI: 10.1016/j.ijmachtools.2003.10.009.

5. Guo Y.B., Warren A.W. (2008) The impact of surface integrity by hard turning vs. grinding on fatigue damage mechanisms in rolling contact. Surface and Coatings Technology, Vol. 2013, No. 3-4, pp. 291-299. DOI: 10.1016/j.surfcoat.2008.09.005.

6. Guo Y.B, Yen D.W. (2004) Hard turning versus grinding - the effect of process-induced residual stress on rolling contact. Wear, Vol. 256, No. 3-4, pp. 393-399. DOI 10.1016/S0043-1648(03)00443-5.

7. Nadolny K. (2013) A review on single-pass grinding processes. Journal of Central South University of Technology, Vol. 20, No. 6, pp. 1502-1509. DOI: 10.1007/s11771-013-1641-5.

8. Nadolny K. (2016) Shaping the cutting ability of grinding wheels with zone-diversified structure. Proceedings of the Institution of Mechanical Engineers,
Part B: Journal of Engineering Manufacture, Vol. 230, No. 2, pp. 254-266. DOI: 10.1177/0954405414554019.

9. Nadolny K., Słowiński B. (2011) The effects of wear upon the axial profile of a grinding wheel in the construction of innovative grinding wheels for internal cylindrical grinding. Advances in Tribology, Vol. 2011, Article ID 516202, 11 pages. DOI:10.1155/2011/516202.

10. Waikar R.A., Guo Y.B. (2008) A comprehensive characterization of 3D surface topography induced by hard turning versus grinding. Journal of Materials Processing Technology, Vol. 197, No. 1-3, pp. 189-199. DOI: 10.1016/j.jmatprotec.2007.05.054

\section{Biographical notes}

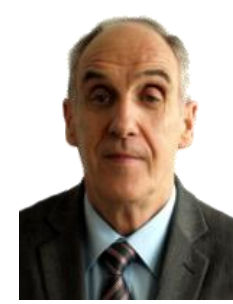

Jarosław Plichta received his M.Sc. degree in Mechanics and Machine Design and next Ph.D as well as the D.Sc. degree and the professor title in Machinery Construction and Operation, in 1976, 1981, 1997 and 2010, respectively. Since 2006 he has been head of the Department of Production Engineering at the Koszalin University of Technology. His scientific interests focus on abrasive processes and tools, monitoring and diagnostics of machining processes as well as metrology. He has managed 4 national research projects, presenting results of his work at many international and national conferences, published more than 120 scientific papers in international and national journals, book chapters, as well as conference proceedings. $\mathrm{He}$ is also the author of 6 monographs, 4 academic textbooks and 11 national patents.

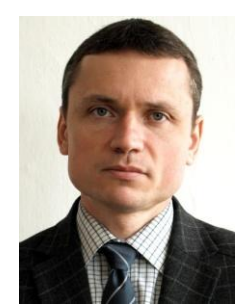

Krzysztof Nadolny received his M.Sc. degree in Mechanics and Machine Design and next Ph.D (with honors) as well as the D.Sc. degree in Machinery Construction and Operation from Koszalin University of Technology, in 2001, 2006 and 2013, respectively. Since 2006 , he has been a researcher in the Department of Production Engineering at the Koszalin University of Technology, where currently he works as an associated professor and the head of research-didactic team for production planning and control. His scientific interests focus on problems concerning machining processes and tools, efficiency, monitoring and diagnostics of machining processes as well as tribology. He has participated in 2 international and 3 national research projects, presenting results of his work at 10 international and 21 national conferences, published more than 200 scientific papers in international and national journals, book chapters, as well as conference proceedings. He is also the author of 4 monographs and 9 national patents.

Sylwester Wojcieszak received his M.Sc. degree in Mechanics and Machine Design in 2013 at the Faculty of Mechanical Engineering of the Koszalin University of Technology. His diploma thesis entitled: "Comparative analysis of surface topography of thermally toughened elements to hardness above 50 HRC after turning and grinding" was elaborated under the direction of Prof. Jarosław Plichta and in consultation with Prof. Krzysztof Nadolny. 